by a progressive increase in the $\mathrm{C}-\mathrm{F}$ bond energy, for which some experimental evidence is now available.

Organic fuorine compounds (M. Stacey). In a general survey of the present position of organic fluorine chemistry, the methods available for the introduction of fluorine into organic compounds were first surveyed. These include the use of reagents such as hydrogen fluoride, antimony trifluoride and other metallic fluorides for the replacement of chlorine, bromine or iodine by fluorine in halohydrocarbons, and the use of fluorides which require elemental fluorine for their preparation. The method of fluorination involving fluorine itself in the presence of a gold- or silver-plated copper catalyst was then considered, and the advantages of the reactive metallic fluorides, such as argentic fluoride or cobalt trifluoride, as agents for the vapour-phase fluorination of organic compounds, were mentioned. It appears probable that this method can be applied under certain conditions to produce fully fluorinated heterocyclic compounds.

A novel polymerization reaction involves the polymerization and simultaneous fluorination of fluorohydrocarbons by fluorine and leads to the formation of stable fluoro-oils. A further interesting development relates to the synthesis of perfluoro adipic acid by the oxidation with potassium permanganate of unsaturated products obtained by the low-temperature fluorination of benzene.

Chemistry of iodotrifluoromethane and iodopenta. fluoroethane (R. N. Haszeldine and Miss J. Banus). The C-I bond in iodotrifluoromethane breaks heterolytically under certain conditions to give reactions involving a 'positive' iodine atom. Thus with potassium hydroxide, fluoroform and not trifluoromethyl alcohol, together with potassium hypoiodite, is obtained. This reaction has been studied radiochemically in alcohol solution. The homolytic fission of the C-I bond in the fluoroiodides yields fluorocarbon radicals such as $\mathrm{CF}_{3}$, and these radicals initiate the chain polymerization of olefines. With ethylene, polymers of the type $\mathrm{CF}_{3}\left[\mathrm{CH}_{2} \mathrm{CH}_{2}\right]_{n} \mathrm{I} \quad(n=1-4)$ have been synthesized; and from these, trifluorohydrocarbons of the general formula $\mathrm{CF}_{3}\left(\mathrm{CH}_{2}{ }_{n} \mathrm{CH}_{3}\right.$ are obtained; polymers of the type $\mathrm{CF}_{3}\left[\mathrm{CF}_{2} \mathrm{CF}_{2}\right]_{n} \mathrm{I}$ ( $n=1-15)$ are likewise formed with tetrafluoroethylene. The fluoroiodides obtained from tetrafluoroethylene have also been converted into oils and greases comparable with fluorocarbons in their stability ; furthermore, these long-chain fluoroiodides act as sources of long-chain fluorocarbon radicals.

The formation of organometallic compounds from $\mathrm{CF}_{3} \mathrm{I}$ and $\mathrm{C}_{5} \mathrm{~F}_{5} \mathrm{I}$ has been achieved, and the com. pounds $\mathrm{CF}_{3} \mathrm{HgI}$ (and derivatives), $\mathrm{Hg}\left(\mathrm{CF}_{3}\right)_{2}, \mathrm{As}\left(\mathrm{CF}_{3}\right)_{3}$, $\mathrm{As}\left(\mathrm{CF}_{3}\right)_{2} \mathrm{I}, \quad \mathrm{S}\left(\mathrm{CF}_{3}\right)_{2}, \quad \mathrm{P}\left(\mathrm{CF}_{3}\right)_{3}$ and $\mathrm{P}\left(\mathrm{CF}_{3}\right)_{3} \mathrm{I}$ were described. The properties and reactions of certain of these compounds were considered, and it was evident that they are useful intermediates for the synthesis of other compounds containing fluorocarbon groups. A further interesting reaction involving fluorocarbon radicals led to the synthesis of trifluoropropyne, a compound of great potential "synthetic value.

Trifluoroacetic acid and its derivatives (J. C. Tatlow). The methods currently available for the synthesis of trifluoroacetic acid, and some of its reactions, were described. The anhydride of this acid has interesting properties. Hydroxyl groups may be trifluoroacetylated, and the unusual properties of sugar trifluoroacetates were revealed. They are unstable compared with normal acetates and are readily hydrolysed by moisture; ethyl alcohol causes alcoholysis to the parent sugar. Since the trifluoroacetyl group is not removed during subsequent tosylation or acetylation reactions in pyridine solution, however, the trifluoroacetyl group may prove to be of use as a 'blocking' group in carbohydrate chemistry.

A mixture of acetic acid and trifluoroacetic anhydride gives sugar and alcohol acetates in good yield ; even cellulose may be acetylated successfully by this method. It is of interest to note that amines form the trifluoroacetyl derivative, and not the acetyl derivative, when treated with a carboxylic acid and trifluoroacetic anhydride.

With nitric acid, trifiuoroacetic anhydride forms an active nitrating mixture, and excellent yields of the nitro derivatives of nitrobenzene, benzonitrile and bromobenzene may be obtained; it appears likely that even aliphatic nitration may occur under mild conditions. The value of trifluoroacetic acid in synthetic organic fluorine chemistry is apparent.

H. J. EMELÉUS

\section{HORMONE ASSAYS}

A SYMPOSIUM on "Hormone Assays" was held on October 20 in London, organised jointly by the Biological Methods Group of the Socioty of Public Analysts and Other Analytical Chemists and by the Society for Endocrinology. Seven papers were read, dealing with the assay of insulin, posterior pituitary, gonadotrophins, thyroid, œstrogens (in man), and with general principles of bioassay. The Biological Methods Group is to be congratulated on its enterprise. Previous symposia organised by the Group have dealt with penicillin assay, the assay of curare and curare. mimetic substances, the evaluation of selective weed. killers and other bioassay problems of general interest. These discussions are, as a rule, published in full in the Analyst. A shortened abstract of the present meeting will also be published in the Journal of Endocrinology.

Although certain hormones may be detected by colorimetric or other chemical reactions, in most cases these are not sensitive enough, and bioassay methods are required. Hormone assays are often conducted without proper regard for the principles of biological assay, and much of the discussion at the meeting was devoted to reconsidering these principles as they apply to hormone assays. In general, bioassays are of two kinds : those in which standard and unknown differ quantitatively, and those in which they differ qualitatively. Assays of the first kind have the same object as chemical determinations, and they are used only where no adequate chemical methods are available. The design of these assays has been greatly improved during the past few years, and they can now be rendered extremely accurate. Particularly satisfactory are those assays in which, as in the standard. ization of insulin, standard and unknown can be relied upon to be pure and have the same chemical composition. Assays of mixed and impure extracts, such as the assay of sex hormones or gonadotropbins in urine, are rather less satisfactory. In these cases more than one active principle is usually present, and there is the danger that the unknown solution may be assayed in terms of a standard of different composition. Prof. J. H. Gaddum discussed some of the difficulties arising in the interpretation of these assays. 
Experiments in which the biological actions of different chemical substances are compared are not always classified as bioassays, but there is no reason why they should be excluded. In practice, they are of the greatest importance, since all preparative pharmacology-the preparation and the determination of activity of new substances-is based on this type of assay. Dr. P. M. F. Bishop's paper showed that such assays can be performed in man and can give consistent results. It must be realized, however, that when different chemical substances are compared, the result of the assay depends on the method, end-point and species used, and any comparative figure is valid only for particular circumstances.

Prof. J. H. Gaddum (University of Edinburgh), the chairman, said that the reason why certain substances are assayed by biological methods is that some drugs, such as insulin, cannot be controlled in any other way, and some drugs, such as acetylcholine, are commonly present in concentrations which are too low to be detected in any other way. Analysts are interested in accuracy and endocrinologists in discovering new facts. The object of the meeting was that endocrinologists should learn accuracy and that analysts should learn something of the difficulties of the endocrinologists. Bioassays should be based on the following principles: 'each assay should consist of a comparison between an unknown preparation and a standard one; each of these preparations should contain the same single active principle and no other substance which modifies its action in the test; each assay should be complete in itself and should involve no arbitrary assumptions about such things as the slope or even the shape of the dose-effect curve, and the limits of the error should be calculated from the internal evidence of each assay.

It is quite impossible to attach any real meaning to the results of assays of unknown mixtures of œstrogens. Estimates which purport to give 'œstrogenic activity' of such mixtures are liable to vary over a thirty-fold range or more, according to the way the test is done. The only possible way of getting results with any intelligible meaning in bioassays of mixtures of œestrogens seems to depend on removing the interfering substances and separating the cestrogens from one another before the biological tests are made. There can be no justification for speaking, as some still do, of 'mouse units' of chorionic gonadotrophin. An international standard preparation of this substance is available, and results should be given in international units. Apart from the provision of reliable preparations of hormones, the contribution which bioassays can make to clinical endocrinology depends on the estimation of hormones in blood and urine. The concentration in the urine may provide an indirect estimate of the daily output of hormone. If, for example, it is found that when a hormone is injected 5 per cent of it appears in the urine, it may be justifiable to make the provisional assumption that the daily output by the gland is equal to the amount excreted in the urine multiplied by twenty. The time will probably come when provision for assays of this kind will be an essential part of the equipment of all large hospitals. The discovery of more sensitive methods is an important objective; at present only chorionic gonadotrophin is present in sufficient concentration to be accurately estimated in both blood and urine.

Dr. H. O. Schild (University College, London) said that digitalis and posterior pituitary are examples of mixed extracts of undefined composition, in which standardization in animals might be misleading. Should these extracts be standardized in man ? Even if the technical difficulties could be completely overcome, there would remain the objection that activity ratios as found in one man and one disease might not apply to others. The problem of standardizing accurately, for human use, mixed extracts containing several related pharmacological principles is essentially insoluble; but animal standardizations may be regarded as a useful safeguard against worthless preparations.

Statistics have immensely improved the planning and interpretation of biological assays. The old nonstatistical methods have, however, not been com. pletely superseded. For example, the old 'bracketing' method, by which standard and unknown are matched by trial and error, is still widely used in research work. This has some justification, since the method involves no assumptions of a mathematical relation between dose and effect. On the other hand, most statistical methods involve some such assumption and for that very reason are subject to certain fallacies.

The measurement of thyroidal activity was discussed by Dr. G. F. Somers (Glaxo Laboratories, Greenford). At present the official British Pharmacopceia method of standardization is based on an estimation of acid-insoluble organically combined (thyroxine) iodine. The United States Pharmacopeia makes use of the total iodine content present in thyroid combination. The British Pharmacopœia method is probably satisfactory for thyroid prepar. ations, but is unsatisfactory for the assay of artificially iodinated proteins and for evaluating the thyroidal activity of thyroxine analogues. For this purpose, biological methods must be used. These are commonly based on the following reactions: (1) changes in respiratory metabolism; (2) decreased susceptibility to anoxia ; (3) loss in body-weight; (4) decrease in susceptibility to toxic substances; (5) premature metamorphic changes in amphibians; (6) restoration and maintenance of growth in thyroidectomized rats; (7) antagonism to goitrogenio drugs. Using the first method, the following relative activities of thyroxine derivatives were obtained : $d l$-thyroxine sodium (standard), 1.0; thyroxine methyl ester, 0.65 ; thyroxine ethyl ester, 0.51 ; N-formyl thyroxine, $0.33 ; l$-thyroxine sodium, 1.95. These figures cannot give a true index of the activity for man, which can only be settled by clinical trial. Dr. Rosalind Pitt Rivers said there is evidence that $d$-thyroxine is active when tested on myxodema patients ; it has $1 / 8$ to $1 / 10$ the activity of $l$-thyroxine.

Dr. J. A. Loraine (University of Edinburgh) said that the anterior lobe of the pituitary produces at least three gonadotrophic hormones. These are the follicle-stimulating hormone, the luteinizing hormone and luteotrophin. In addition, there are two im. portant gonadotrophins : chorionic gonadotrophin elaborated by the human placenta with predominantly luteinizing action, and pregnant mares serum gonadotrophin, which is predominantly folliclestimulating. Animal tests for the assay of chorionic gonadotrophin may be divided into primary and secondary, according to whether the organs inspected are the gonads themselves or organs affected secondarily by the liberation of cestrogens or androgens from the gonads. The primary tests register effects on corpora lutea, ovarian weight, ovarian hyperæmia in rats, rabbit ovulation and xenopus; the secondary tests on uterine weight, vaginal smears, 
vaginal smears in B-deficient rats, seminal vesicles and prostatic weight. Dr. Loraine has found the assay depending on prostatic weight to be convenient and sensitive. An advantage of this test is that the oestrogens normally present in pregnancy urine do not interfere w:th the assay. By this method 20,000 40,000 I.U. of chorionic gonadotrophin appeared to be excreted in twenty-four hours from the fortieth to eightieth day of pregnancy and less than 10,000 I.U. after the third month. The estimation of gonadotrophins in the urine of men, non-pregnant women and children is at present unsatisfactory. Dr. Annie M. Hain (Manchester) and Dr. G. I. M. Swyer (London) discussed the production of gonadotrophins in testicular tumours. These may be derived from two sources, the patient's anterior pituitary and the tumour.

In discussing the assay of insulin, Mr. K. L. Smith (Boots, Ltd., Nottingham) said that this is done either by a fall in blood sugar in rabbits or by the incidence of convulsions in mice. The accuracy of the mouse method is such that the use of some eight hundred mice should give an estimate accurate to \pm 10 per cent at $P=0.95$. It would require 240 rabbit responses to obtain the same accuracy by the blood-sugar method.

The assay of posterior pituitary lobe extracts was considered by Mr. G. A. Stewart (Wellcome Laboratories, Dartford). The oxytocic principle is usually assayed by the guinea-pig test in vitro; but this assay may be misleading since the guinea-pig uterus reacts also to vasopressin. Moreover, the sensitivity to vasopressin varies according to the hormonal state of the uterus and the magnesium concentration of the solution. Oxytocin may be satisfactorily assayed by the fall of blood pressure produced in chickens; this test is not normally affected by vasopressin.

Miss M. H. I. Macauley mentioned the anæsthetized rat method for assaying vasopressin, which is found to be sensitive, specific and discriminating.

The clinical methods of assaying cestrogens were discussed by Dr. P. M. F. Bishop (Chelsea Hospital, London). When the stilbene group of synthetic œestrogens was introduced by Dodds and his coworkers, their relative potency was tested on the vaginal smear changes of castrated rats and mice. Hexœestrol and dienœestrol were found by these tests to be more potent than stilbostrol. Clinical experience soon gave rise to the impression that these ratios of potency might not hold good in the human subject. In trying to compare these drugs in man, the following end-points were submitted to scrutiny : (1) the hot flush count in menopausal women; (2) the vaginal smear in menopausal women; (3) the induction of œestrogen-withdrawal bleeding. Only the third proved a practicable assay method. The general plan was that $2 \mathrm{mgm}$. stilboestrol were administered daily by mouth for a fortnight to chosen cases of amenorrhœa. Depending on whether œestrogen-withdrawal bleeding took place or failed to do so, the dose was lowered to $1 \mathrm{mgm}$. or increased to $3 \mathrm{mgm}$. daily for fourteen days. The mean of the two doses which just failed and just succeeded was taken as the therapeutic unit. In the same patient a therapeutic unit for another cestrogen was then established.

A thousand courses of œestrogen have been administered, and the results are remarkably consistent. Dienostrol was found to be about a quarter, and hexcestrol about an eighteenth, as potent as stilbœstrol. It should be emphasized that these ratios of ostrogenic potency only apply to women in the age-group of maturity, suffering from amenorrhœa. There is no guarantee that the same ratios would hold, for example, for the response to cestrogens of women of menopausal age or of men with prostatic carcinoma.

Dr. W. A. Broom (Nottingham) said that the results of his assays in rats on stilboestrol, hexcestrol and dienoestrol agree well with Dr. Bishop's clinical results. However, with ethinyl œstradiol the agree. ment ceases, since in rats this substance is five times less active than stilbœestrol, while clinically it is 100 200 times more active.

H. O. SCHILd

\section{IRRADIATION OF MIXED TISSUES}

\author{
By DR. W. H. LOVE \\ Department of Physics, University of Sydney
}

A $\mathrm{N}$ examination of the various researches that A have been made into the quantitative effects of radiations on cells and tissues shows that the relation. ship between $q$, the radiation dose, and $P$, the proportion of cells of a given type $T_{1}$ that survive the dose $q$, is represented by a sigmoid curve $A_{1}$ (Fig. 1).

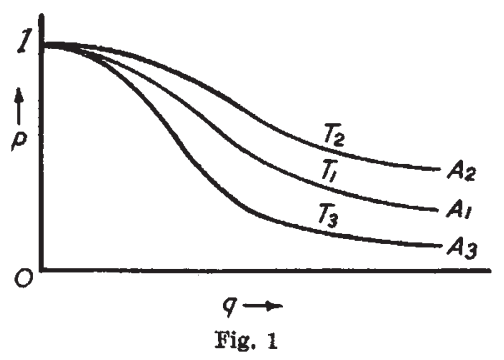

If cells of type $T_{\mathrm{a}}$ are less 'radio-sensitive' than those of type $T_{1}$, and if cells of type $T_{3}$ are more sensitive than those of type $T_{1}$, then it seems to have been generally assumed that the survival curve $A_{\text {, }}$ for type $T_{2}$ will be everywhere above $A_{1}$ and that the survival curve $A_{3}$ for type $T_{3}$ will be everywhere below $A_{1}$.

The object of the present communication is twofold : (i) to show that the curves may cross, and (ii) to pursue some of the immediate consequences of (i).

If a tissue of given type is acted upon by radiation of a given quality, it is known that the fractional survival $P$, associated with a dose $q$, is determined by $f n(>q)$, the first $n+1$ terms of the Poisson series in $\lambda q$, where $n$ and $\lambda$ are characteristic of the tissue and the quality of the radiation.

Let $A_{1}$ (Fig. 2) be the survival curve for tissue $T_{1}$ characterized by $n_{1}$ and $\lambda_{1}$, and let $A_{2}$ be the survival curve for tissue $T_{2}$ characterized by $n_{8}$ and $\lambda_{2}$. Then if $n_{2}>n_{1}$ and $\lambda_{2}<\lambda_{1}$ the curve $A_{2}$ will be every. where above $A_{1}$ and the survivals will be determined by :

$$
P_{1}=f n_{1}\left(\lambda_{1} q\right), P_{2}=f n_{2}\left(\lambda_{2} q\right) .
$$

Consider now a third tissue $T_{3}$ the cells of which are characterized by $n_{2}$ and $\lambda_{3}$, and suppose that $\lambda_{3} / \lambda_{2}$ is some proper fraction equal, for example, to the ratio $q_{2} / q_{1}$. Then its survival curve $A_{3}$ will be determined by :

$$
P_{3}=f n_{2}\left(\lambda_{2} \frac{q_{2}}{q_{1}} q\right)
$$

